\title{
Reasonable Pumping Depth for Drainage and Gas Recovery of Shale Gas Wells
}

\author{
Jianda Chen ${ }^{1}$, Dajiang Wang ${ }^{1}$, Zhiquan Zhang ${ }^{2}$, Jie Liu ${ }^{2 *}$ \\ ${ }^{1}$ Petroleum Engineering Technology Research Institute of SINOPEC Jianghan Oilfield, Wuhan 430035, China \\ ${ }^{2}$ School of Petroleum Engineering, Yangtze University, Wuhan 430100, China
}

Corresponding Author Email: LiuJie@ Yangtzeu.edu.cn

https://doi.org/10.18280/ijht.380314

Received: 7 May 2020

Accepted: 21 July 2020

\section{Keywords:}

shale gas well, inflow curve, outflow curve, critical liquid-carrying flow, setting depth of the pump

\begin{abstract}
For shale gas wells, in the initial production stage, the liquid production is large, and the lifting process is needed to assist the drainage. However, for gas wells, especially shale gas wells, the ultimate purpose is different from that of oil wells, and the current design method of pumping depth cannot meet the field requirements. Starting from the production characteristics of liquid-producing gas wells, this paper analyzed the gas well productivity, wellbore pressure distribution and critical liquid-carrying flow, and adopted the node analysis method to propose a design method for the pumping depth of shale gas wells during drainage and gas recovery. Then, the proposed method was applied to optimize the design of the jet pump of well A in Block JY, according to the design results, the pump was started for production; after the wellbore liquid level was raised to the designed depth, the gas well can conduct annulus space liquid-carrying production, and the production effect of well A showed that, the proposed method can be applied as a method for optimizing the technological parameters of shale gas wells.
\end{abstract}

\section{INTRODUCTION}

Currently, the existing methods for determining the pumping depth in the lifting process mostly adopt the suckerrod pumps, and the commonly used methods include the empirical method, the submergence determination method, and the system efficiency determination method. Wherein the empirical method [1] selects a certain submergence degree value according to existing experience and determines the pumping depth based on data such as the output of the oil wells, the gas-oil ratio, and the crude oil viscosity, etc. The submergence determination method [2-6] makes use of the positive correlation between the pump efficiency and the fullness coefficient of the pump, and it uses the relationship between the fullness coefficient of the pump and the submergence pressure to determine the pumping depth; there're many researches on the relationship between the degree of submergence and the efficiency of the pump. The system efficiency method takes the system efficiency or economic benefit as the objective functions to optimize the pumping depth, it decomposes the system efficiency into two parts: the ground efficiency and the downhole efficiency, and the downhole efficiency is actually the efficiency of the pump. However, for gas wells, especially shale gas wells, the main purpose of applying the lifting process to drainage and gas recovery is gas production, and the above-mentioned pumping depth determination methods cannot be applied to shale gas. According to the characteristics of gas well drainage and gas recovery technologies, this paper applied the production system node analysis method to design the setting depth of pumps in the process of drainage and gas recovery.

\section{INFLOW DYNAMIC ANALYSIS OF SHALE GAS WELLS}

The large-scale development of shale gas benefited from the significant advancement in horizontal well completion and segmented volume fracturing reconstruction technologies. After a horizontal well is fractured in segments, an extremely complex fracture grid system will be created, and these fracture grids will greatly improve the permeability of the reservoirs within the fracturing communication range, enabling the originally abnormally dense shale reservoirs to be effectively connected to the wellbore, so that the development of shale gas could have commercial values [7-9]. The desorption effect of adsorbed gas and the complex fracture network formed after segmented fracturing make the shale gas wells exhibit different dynamic production characteristics from the conventional gas wells $[10,11]$.

For the productivity test of gas wells with conventional gas well standards, generally, a pressure gauge is directly put to the bottom of the well to record the pressure change data, so the productivity results calculated based on the measured bottom hole pressure data could be more accurate and reliable. However, since the shale gas wells have a large fracturing fluid flowback in early drainage and gas recovery stage, the gas wells do not have the conditions for putting the pressure gauge into the bottom hole to measure the flowing pressure, and it's difficult to conduct wellbore calculation based on the wellhead pressure and the production data. Moreover, since the productivity of gas wells declines rapidly, the initial production cannot accurately reflect the production capacity of gas wells, but only reflect the characteristics of the main fractures formed in the SRV, especially after fracturing. Therefore, the research block had chosen the time when the production is relatively stable to conduct back pressure test. 
The test data of Well A is shown in Table 1, since the condition for pressure gauge setting could not be met, the bottom hole pressure was calculated using the Pipesim software based on the wellhead oil pressure, and the gas and liquid production.

Table 1. Backpressure test data of Well A

\begin{tabular}{cccccc}
\hline Test time & $\begin{array}{c}\text { Oil nozzle } \\
(\mathbf{m m})\end{array}$ & $\begin{array}{c}\text { Casing pressure } \\
(\mathbf{M P a})\end{array}$ & $\begin{array}{c}\text { Daily gas production } \\
\left(\times \mathbf{1 0}^{\mathbf{4}} \mathbf{m}^{\mathbf{3}} / \boldsymbol{d}\right)\end{array}$ & $\begin{array}{c}\text { Daily liquid production } \\
\left(\boldsymbol{m}^{\mathbf{3}} / \boldsymbol{d}\right)\end{array}$ & $\begin{array}{c}\text { Bottomhole flowing pressure } \\
\boldsymbol{M P a}\end{array}$ \\
\hline November 22-23 & 10 & 8.15 & 7.6 & 113 & 16.18 \\
November 24 & 12 & 7.8 & 10.2 & 184 & 15.85 \\
November 25 & 14 & 8.84 & 14.7 & 100 & 15.00 \\
\hline
\end{tabular}

Test data analysis mainly has the pressure square form and the pseudo-pressure form, including binomial, exponential and one-point expression methods. According to the shale gas steady-state seepage model of equivalent fractured horizontal well, both binomial and exponential expression methods are applicable methods for productivity evaluation of horizontal shale gas wells. This paper adopted the exponential expression method to process the test data, the processing results are shown in Figure 1, and the obtained productivity equation of Well A is:

$$
Q_{s c}=4.95 \times 10^{-5}\left(P_{r}^{2}-P_{w f}^{2}\right)^{2.194}
$$

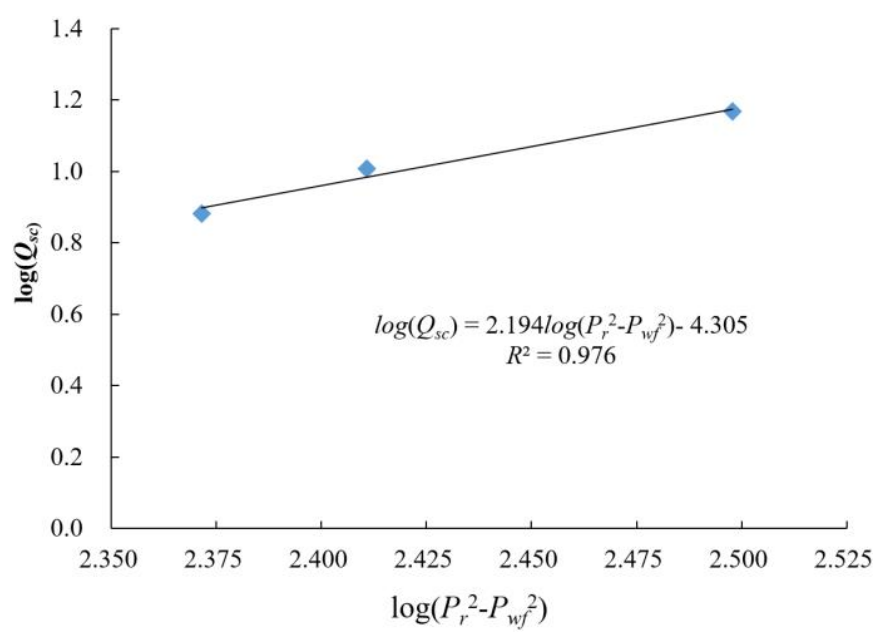

Figure 1. Exponential productivity equation of Well A

\section{WELLBORE PRESSURE DISTRIBUTION OF SHALE GAS WELLS}

Figure 2 shows the wellbore pressure during the production of liquid-accumulating well and its distribution. In the process of drainage and gas recovery of gas wells, generally, the oil tube produces the liquid and the oil jacket annular space produces the gas. Therefore, the pressure distribution in the oil jacket annular space was divided into two sections with the gas-liquid interface as the dividing surface. Below the dividing surface, a static liquid column was formed due to the accumulation of liquid, the pressure was generated due to the liquid gravity, and the pressure gradient was approximately the pressure gradient of the static liquid column; above the dividing surface, there're gas-liquid two-phase flows, and the gas-liquid ratio was greater than that below the dividing surface, so the pressure gradient was significantly lower than the pressure gradient below the dividing surface.

According to Figure 2, when the liquid-accumulating gas well produces normally, the pressure balance formula is:

$$
P_{w h}+G_{f a} L+G_{f b}(H-L)=P_{w f}
$$

where, $P_{w h}$ is the wellhead pressure, MPa;

$G_{f a}$ is the average pressure gradient above the gas injection point, $\mathrm{MPa} / \mathrm{m}$;

$G_{f b}$ is the average pressure gradient below the gas injection point, $\mathrm{MPa} / \mathrm{m}$;

$H$ is the depth of the middle of the oil layer, m;

$L$ is the depth of gas-liquid interface, m;

$P_{w f}$ is the bottom hole flowing pressure, $\mathrm{MPa}$.

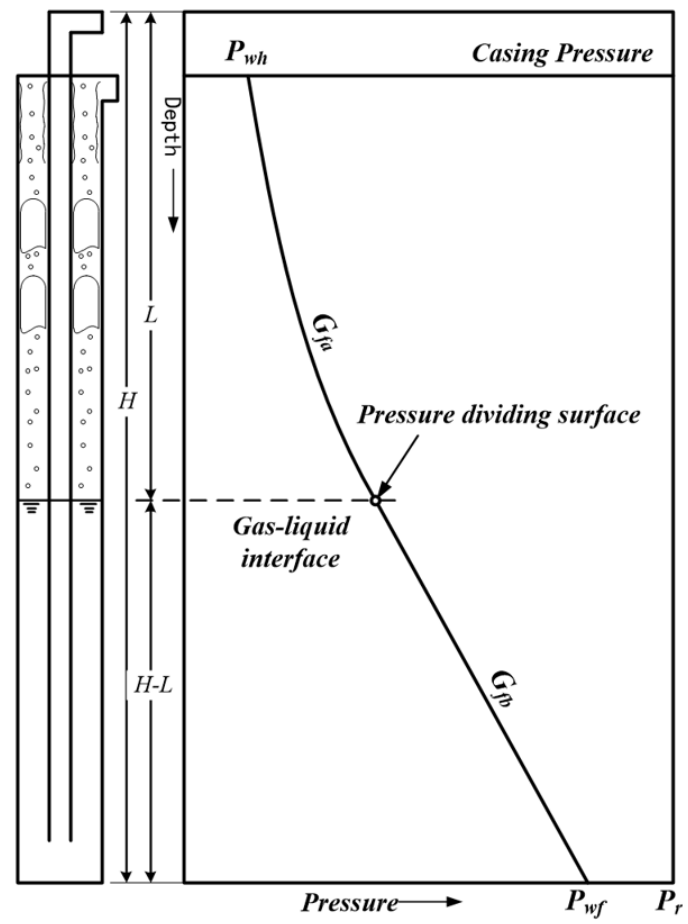

Figure 2. Wellbore pressure distribution in the liquidaccumulating gas well

When designing and analyzing, the pressure distribution in the oil tube was calculated using the wellbore multiphase flowing pressure distribution and the static liquid column calculation. Therefore, even if the gas production, liquid production, and wellhead pressure of the gas well are the same, for different fluid accumulation height in the wellbore, the corresponding bottom hole pressures are also different. As shown in Figure 3, the wellhead pressure of Well A was $7.8 \mathrm{MPa}$, the gas production was $10.2 \times 10^{4} \mathrm{~m}^{3} / \mathrm{d}$, and the liquid production was $173 \mathrm{~m}^{3} / \mathrm{d}$. When the gas well produced normally and the vertical depth of the liquid level was respectively $2800 \mathrm{~m}, 2600 \mathrm{~m}, 2400 \mathrm{~m}, 2200 \mathrm{~m}$, and $2000 \mathrm{~m}$, the corresponding hole bottom flowing pressure was $19.77 \mathrm{MPa}$, 19.87MPa, 20.83MPa, 21.83MPa, 22.94MPa and 24.25MPa, respectively. 


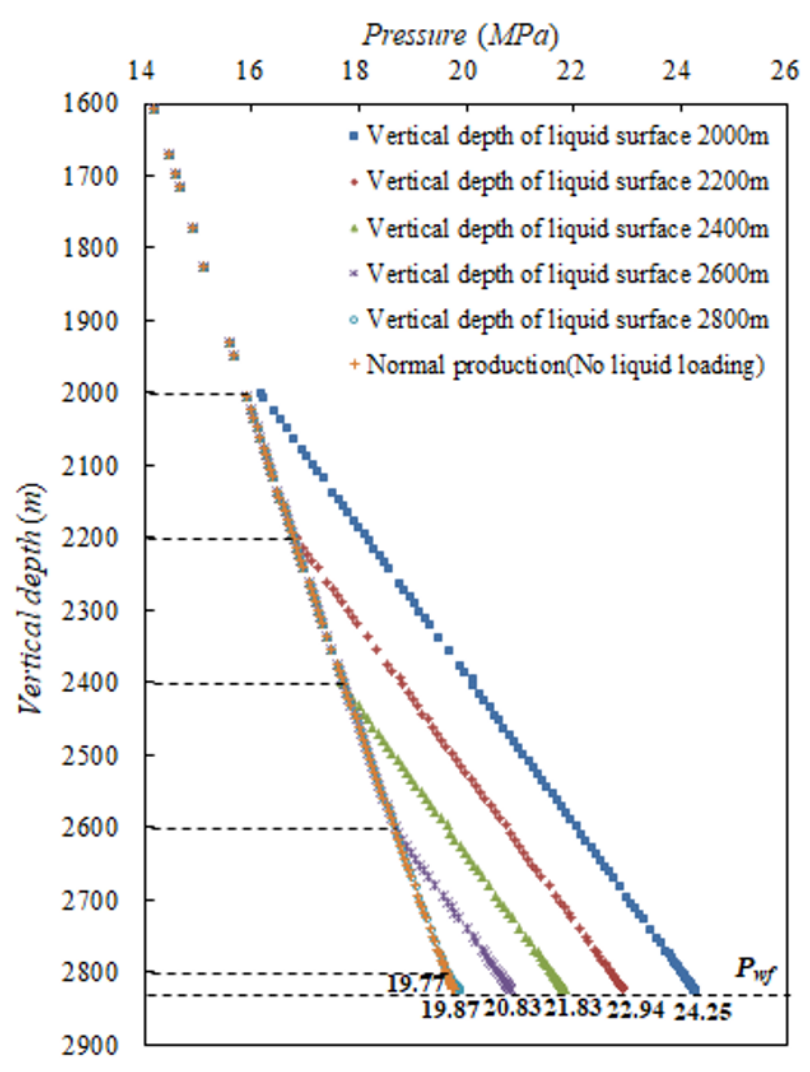

Figure 3. Wellbore pressure distribution at different liquid surface depths in Well A

\section{CRITICAL LIQUID-CARRYING FLOW OF SHALE GAS WELLS}

Liquid accumulation in gas wells refers to the phenomenon that liquids accumulate in the wellbore since the gas cannot carry out the liquid effectively. During the production process, in the gas well, the two phases of gas and liquid flow out of the stratums and are collected from the ground through the wellbore. In the early stage of production, the gas production of the gas well was high, the gas-liquid two phases flowed upward in a circular flow, and the liquid was carried in two forms: droplets entrained in the gas core and the liquid film attached to the pipe wall. As the stratum pressure drops, the gas production of the gas well decreases, resulting in reversal of the liquid flow (droplets/liquid film) in the wellbore, the liquid cannot be taken out from the ground, and thereby accumulated in the wellbore. Moreover, the liquid accumulation in the wellbore would greatly increase the pressure gradient of the wellbore, which will greatly increase the decline in production and affect the final recovery rate of the gas well. In order to accurately predict the liquid accumulation time of gas wells, Turner et al. [12] proposed a droplet reversal model, which assumed the droplets were spherical, and the drag coefficient of the gas core for the droplets and the maximum Weber number of the droplets took 0.44 and 30 respectively; for safety reasons, a factor of 1.2 was added to the model. Aiming at the coefficient problem, Coleman et al. [13] conducted research on fluid accumulation in gas wells with a wellhead oil pressure lower than 500 psi and found that the Turner model with no added safety factor was more in line with the prediction of liquid accumulation in low-pressure gas wells. However, Guo et al. [14] believe that the force balance of the droplets only makes the droplets suspend in the gas well and is not enough to carry the droplets out, only a larger gas flow rate can prevent the wellbore from accumulating liquid. On the basis of the Turner model, a flow coefficient of 1.2 should be added to the model. Nosseir et al. [15] believe that, under different flow patterns (laminar flow/transitional flow/turbulent flow), the drag coefficients of the gas core for the droplets are different, and the droplet size and shape still adopted the assumption of the Turner model. Li et al. [16] believe that the pressure difference between the front and back of the droplets in the gas core causes the pressure difference on its surface, making the droplets deform into an ellipsoid shape, which leads to a larger force area, and the critical liquid-carrying flow rate calculated by the model was only $38 \%$ of the result calculated by the Turner formula. Based on Li Min's model and the conclusion that the internal energy change of the droplets during deformation process was equal to the work done outwards, combining with the definition of the Weber number, Wang and Liu [17] strictly derived the relationship between the characteristic parameters of droplet deformation and the critical Weber number through integration, and obtained the new coefficient with maximum droplet size and droplet deformation taken into consideration. In addition, they established a minimum critical liquidcarrying gas volume model for spherical cap-shaped droplets. As for the equal relationship between the total surface energy of droplets in the gas flow and the turbulent flow energy of the gas, Tan et al. proposed a new model that considers the influence of liquid volume and maximum droplet diameter on the critical flow of the carrying liquid.

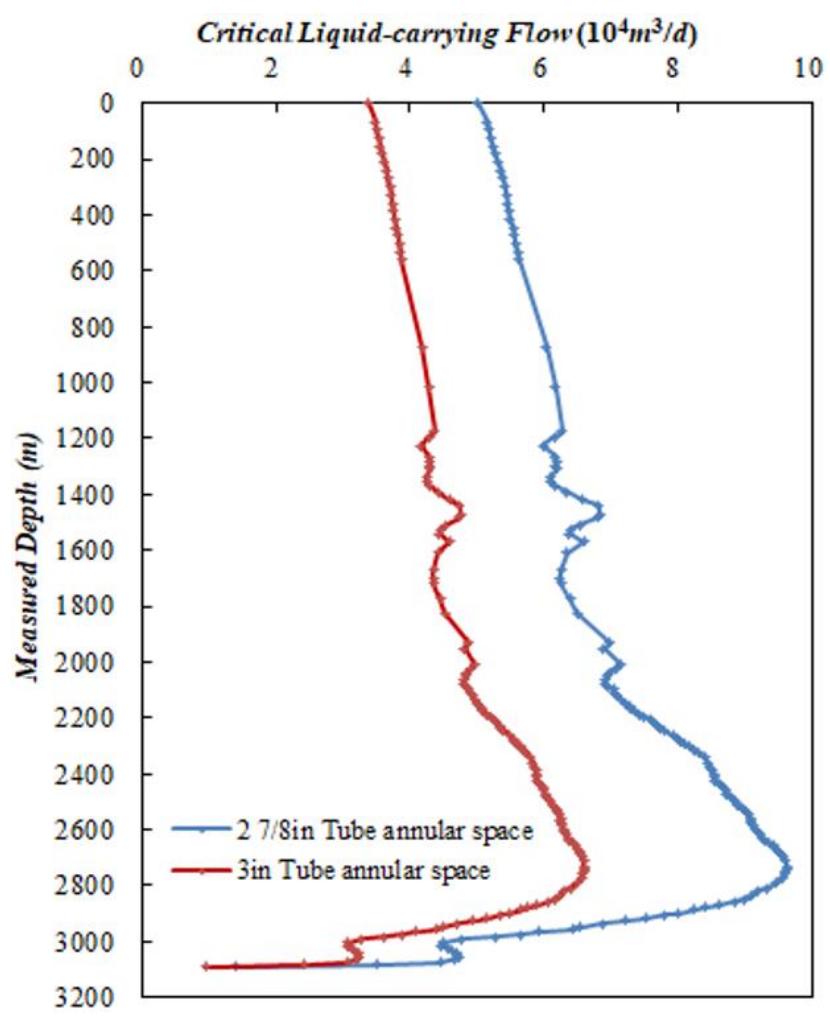

Figure 4. Distribution of critical liquid-carrying flow in the annulus space of the oil jacket during the production of different oil tubes in Well A

All of the models mentioned above were established for vertical gas wells, and there are few relevant studies concerning the horizontal wells. Belfroid et al. added an angle correction term based on the Turner model, but they believe 
that the liquid film inversion is the root cause of liquid accumulation [18-20]. Shi et al. [21] carried out experiments to observe the change of droplet shape with size under different inclination angles, and proposed a critical liquidcarrying gas volume model based on the "half-hamburger"shaped droplets in vertical sections, inclined sections and horizontal sections. Fadili et al. proposed that, after a droplet collided with the wall of the oil tube, its movement direction was changed, its speed before the collision could be calculated according to the collision energy loss, namely the critical liquid-carrying gas flow rate.

This paper started from the critical liquid-carrying gas flow rate model of vertical wells. First, it corrected the model with the Belfroid angle correction term, and used the actual production data of 132 well times to analyze the error of the model. Since the maximum liquid-carrying flow in the wellbore of highly inclined wells appears in the most difficultto-carry position, rather than at the wellhead or the bottom
(Figure 4), the value calculated by the mathematical model was the maximum liquid-carrying flow of the well.

The calculation results are shown in Figure 5. After the Turner, Coleman, and Nosseir models were subject to the Belfroid angle correction, the calculation results of the $\mathrm{BT}, \mathrm{BC}$, and $\mathrm{BN}$ models were significantly higher than the actual production data, and the calculation results of the BL and $\mathrm{BW}$ models were significantly lower than the actual production data. Since the existing model had greater errors, through model correction, this paper constructed a new mathematical model of critical liquid-carrying flow for gas wells in the target block, and the calculation results of the corrected model were in good agreement with actual production data, with an average error of only $6.41 \%$.

$$
v_{c r}=2.87\left[\frac{\sigma\left(\rho_{l}-\rho_{g}\right)}{\rho_{g}^{2}}\right]^{0.25} \frac{(\sin (1.7 \theta))^{0.38}}{0.74}
$$

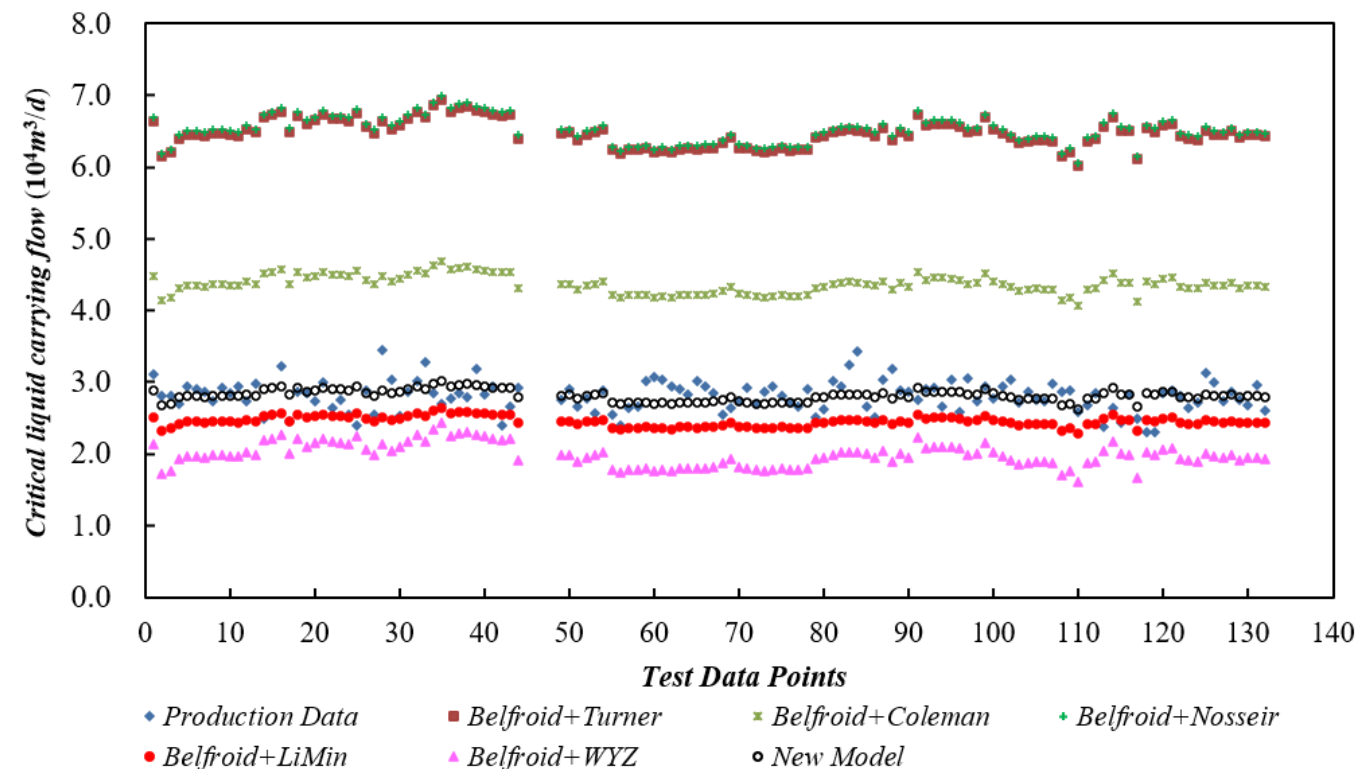

Figure 5. Calculation results of the block critical liquid-carrying flow model (the black circles in the figure are the calculation results of the new model)

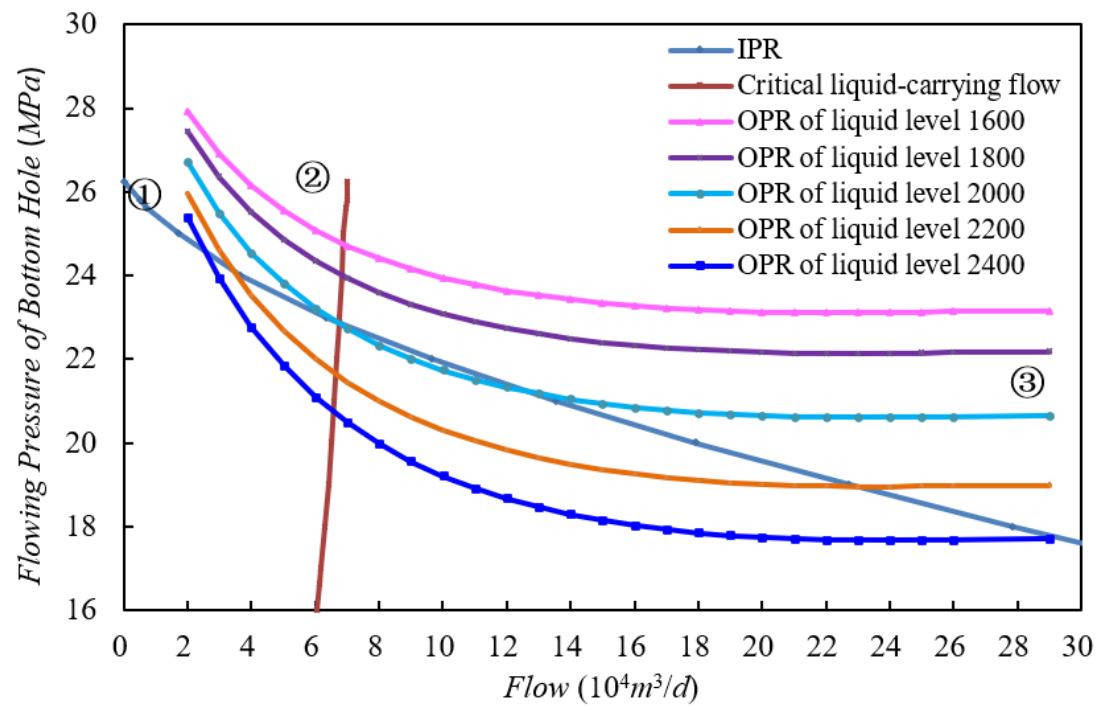

Figure 6. Production system node analysis diagram of well A 


\section{PRODUCTION SYSTEM NODE ANALYSIS}

Node analysis is a system analysis method that can optimize the production system of oil wells or gas wells. This method calculates and analyzes each component of the production system to obtain the most ideal output and the highest economic benefits.

In order to effectively optimize the production system, it is necessary to analyze each flowing part in the production system. The influence of any changes in the flowing process is very important and can be displayed using graphs. In the process of system analysis, first, a solution node is selected, this node divides the system into two parts, the inflow part, and the outflow part. The inflow part is the flowing process of the fluid from the start node to the solution node, and the outflow part is the flowing process of the fluid from the solution node to the end node. Subsequently, the relationship between the flow of each part and its pressures is established, to determine the flow, two prerequisites must be met: one is that the flow of the inflow node is equal to the flow of the outflow node; the other is that the node has and only has one pressure value. The solution node is determined, and the pressure of the node can be calculated from the start node or the end node to the solution node. The calculation formula is:

$$
\begin{gathered}
P_{r}-\Delta P_{\text {Inflow part }}=P_{\text {node }} \\
P_{w h}+\Delta P_{\text {Outflow part }}=P_{\text {node }}
\end{gathered}
$$

In the above formula, the pressure drop of the inflow part $\Delta \mathrm{P}$ will change with the change of flow $\mathrm{q}$, therefore, the flow and pressure will form a curve; in the same way, the pressure drop of the outflow part will also change with the change of flow, which will give another curve, and the intersection of the two curves can meet the above two prerequisites.

The production optimization of gas wells using node system analysis includes the selection of lifting process, the optimization of the design, and the selection of oil tube types, etc. In general, node analysis can be used for gas well production prediction, liquid accumulation diagnosis, determination of drainage and gas recovery timing, and optimization of drainage and gas recovery techniques. This paper adopted the method of node analysis in the production system to analyze the setting depth of the pump in the drainage and gas recovery process, as shown in Figure 6.

In Figure 6, Curve (1) is the inflow dynamic curve of the solution node selected at the bottom of the well, which was obtained by processing the back pressure test data of Well A. However, due to the lack of test points during the well test process and the large fluid production, it exhibited characteristics of a very rapid decline in the production when the production of gas wells is relatively low, reflecting the influence of wellbore liquid accumulation on gas well production. Curve (2) is the critical liquid-carrying flow corresponding to different pressures at the position where the liquid is the most difficult to carry in the wellbore. The value was calculated according to Formula (3). The physical meaning of the intersection with the Curve (1) is that the flow of gas produced in the reservoir is just enough to carry the liquid to the wellhead. Curve (3) is the outflow dynamic curve when the solution node was selected at the bottom of the well, it was obtained according to the calculation method of the annulus space pressure distribution of the liquid accumulation wellbore in Well A. It can be seen from the curve shape that with the increase of gas well production, the bottom hole pressure decreased first and increased later, this is because when the gas well production was small, the pressure loss during gas-liquid flow was mainly affected by gravity; when the gas well production increased to a certain value, the pressure loss was mainly affected by the fracture force.

For different liquid level depth, the shapes of the corresponding outflow dynamic curves are different as well, and the physical meaning of the intersection point with the inflow dynamic curve is that the gas produced by the reservoir is just lifted to the ground through the annular space of the oil jacket. When the liquid level depth was $1600 \mathrm{~m}$ and $1800 \mathrm{~m}$, there's no intersection between the outflow dynamic curve and the inflow dynamic curve. This is because the high liquid accumulation in the wellbore resulted in a large pressure loss during fluid flowing and the reservoir could not rely on its own energy. When the liquid level depth was $2000 \mathrm{~m}, 2200 \mathrm{~m}$ and $2400 \mathrm{~m}$, the outflow dynamic curve and the inflow dynamic curve had two intersections. One intersection was on the left side of the minimum value of the outflow curve, which was an unstable flow that won't occur in reality; the other intersection point was on the right side of the minimum value of the outflow curve, which was a stable flow. Therefore, the intersection on the right side was chosen for the node analysis.

Using gas well node analysis, the production status of the gas well in Figure 6 could be analyzed. If the intersection of curves (1) and (3) is on the right side of the intersection of curves (1) and (2), it indicates that the gas well production is greater than the critical liquid-carrying flow, and the gas well can conduct normal liquid-carrying production; if the intersection of curves (1) and (3) is on the left side of the intersection of curves (1) and (2), it indicates that the gas well production is less than the critical liquid-carrying flow, and the gas well cannot rely on its own energy to conduct liquidcarrying production, liquid will accumulate in the wellbore during the production process; if the intersection of curves (1) and (3) and the intersection of curves (1) and (2) coincide, it indicates that the gas well production can just meet the requirements of liquid-carrying production.

Since the liquid produced by the shale gas wells is the well control fluid, with the progress of the production, the cumulative flowback of the fracturing fluid increases, the liquid production of the gas well will gradually decrease, the gas-liquid ratio will increase, after the production reaches the steady state, the lifting process is no longer needed, and the gas well can rely on its own energy to conduct normal liquidcarrying production. Therefore, when designing the setting depth of the pump, the goal is to ultimately meet the requirements of the normal liquid-carrying production of the gas well; in the node analysis diagram, determine the intersection of the gas well production and the critical liquid carrying flow, then determine the corresponding wellbore liquid level depth, and this depth should be taken as the setting depth of the pump in the drainage and gas recovery process. In fact, it is the intersection of curve (1), curve (2) and curve (3) determined in the node analysis diagram.

\section{EFFECT ANALYSIS OF JET PUMP IN WELL A}

In Well A, a pressure gauge was set to the depth of $3000 \mathrm{~m}$ on September 21, 2018. The measured downhole pressure was 
27.23 $\mathrm{MPa}$, there's no pressure at the wellhead, the pressure coefficient was 0.908 , and the liquid level depth was $260 \mathrm{~m}$. The well was an atmospheric gas well; it had a maximum liquid production of $144 \mathrm{~m}^{3} / \mathrm{d}$, a low gas-water ratio of $424 \mathrm{~m}^{3} / \mathrm{m}^{3}$, the casing in the wellbore was intact, and there's no well completion oil tube.

Using the above-mentioned node analysis method, the inflow dynamic curve, the outflow dynamic curve, and the critical liquid-carrying flow of well $\mathrm{A}$ intersected at a point $\left(6.136 \times 10^{4} \mathrm{~m}^{3} / \mathrm{d}, 16.63 \mathrm{MPa}\right)$, that is, when the bottom hole flowing pressure was $16.63 \mathrm{MPa}$, the corresponding gas well production $6.136 \times 10^{4} \mathrm{~m}^{3} / \mathrm{d}$ had just guaranteed the liquidcarrying production. At this time, the corresponding wellbore liquid level depth was $2050 \mathrm{~m}$, that is, when the setting depth of the pump was $2050 \mathrm{~m}$, the gas well can conduct normal liquid-carrying production. To ensure that the bottom hole pressure can meet the liquid-carrying production, the setting depth of the pump was designed to be $2100 \mathrm{~m}$.

The construction preparation works of the well was began on April 20, 2019, then ground equipment, downhole machine units, tools, and oil tubes arrived at and entered the construction site one after another. The well-killing started on May 10, and the string was set on May 13-16. During the killing and string-setting, the total liquid volume in the well was $210 \mathrm{~m}^{3}$, and there's no pressure at the wellhead. The pump was started on May 29, an intermittent production method was adopted for drainage and gas test. As of about 11 o'clock on June 4 , the pump was started for a total of 10 hours. When the liquid production of the stratums reached $28 \mathrm{~m}^{3}$, gas was produced from the annulus space of the two oil-tubes of the gas well, at this time, the gas output was about $2 \times 10^{4} \mathrm{~m}^{3} / \mathrm{d}$, the flame height was about $4 \mathrm{~m}$. At 17:00 in the afternoon, the casing pressure rose to $8 \mathrm{MPa}$. When the pump was started, the dynamic liquid level was expected to be $167 \mathrm{~m}$, and the pump efficiency was higher. At the same time as the hydraulic jet pump pumped the water, the stratums produced liquid as well. The liquid pumping speed was greater than the stratum liquid output speed, and the dynamic liquid level dropped fast.

At 11:10 am on June 6, the rectification of the centrifugal pump was completed, and the pump was initiated to start the production. The pump production time was $4.2 \mathrm{~h}$, the pump pressure was $13-15.2 \mathrm{MPa}$, the casing pressure rose from $12 \mathrm{MPa}$ to $17 \mathrm{MPa}$, and the flame height was $5-6 \mathrm{~m}$. The estimated production was $3 \times 10^{4} \mathrm{~m}^{3} / \mathrm{d}$. During the entire production process, under the action of the jet pump, the dynamic liquid level dropped, the stratums produced both gas and liquid, the back pressure of the oil jacket annulus space liquid column to the stratums decreased, and the casing pressure rose faster. On June 7, the ultrasonic dynamic liquid level was measured, and the dynamic liquid level was about $2045 \mathrm{~m}$. The data showed that the liquid in the well above the setting depth of the pump had been lifted out of the wellbore by the jet pump.

The well had once been shut down due to limited sales. On August 30, 2019, the production was continued, and the production curve is shown in Figure 7. On November 14, the small annulus space production was altered to bigger annulus space production, and jet pump liquid drainage was conducted on the $14^{\text {th }}$, the $20^{\text {th }}$, and the $25^{\text {th }}$. According to the production data, the pump-start and draining stage can effectively drain the liquid in the wellbore, which had increased the gas well production to a certain extent, but since the current gas production of the gas well was greater than the critical liquidcarrying flow, the production increment effect was not obvious.

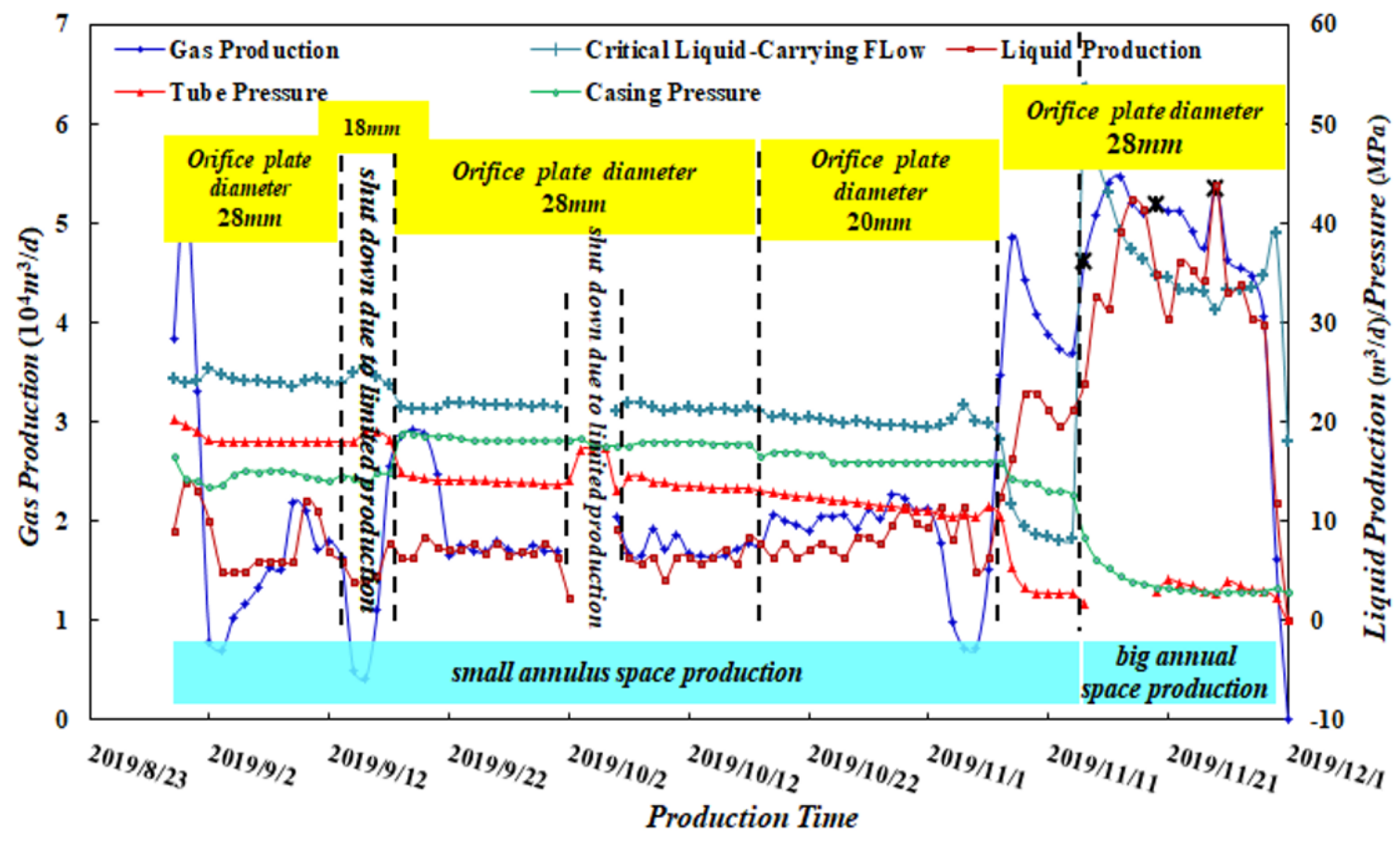

Figure 7. Production data curve of Well A

\section{CONCLUSIONS AND RECOMMENDATIONS}

(1) The liquid produced during the drainage and gas recovery of shale gas wells is mainly the fracturing fluid. As the cumulative flowback of fracturing fluid increased, the liquid production of the gas well gradually decreased, and finally the gas well reached the state of relying on its own energy to conduct liquid-carrying production;

(2) The initial fluid production of shale gas wells was large, pressure gauge couldn't be set into the bottom hole to measure 
the downhole flowing pressure, so the productivity of the gas well could not be reflected accurately; after the production was stable, back pressure well testing was performed, and the binomial expression or exponential expression was adopted to analyze the test data.

(3) The critical liquid-carrying flow of horizontal shale gas wells appeared at the $50^{\circ}$ inclination angle position, and the drag coefficient was between Li Min's model and the Turner model;

(4) In the gas well production system analysis, the bottom hole was selected as the solution point, then the intersection of the inflow dynamic curve, the outflow dynamic curve, and the critical liquid-carrying flow was the critical point for the gas well to conduct normal liquid-carrying production, and the liquid level depth corresponding to the outflow curve could be taken as the reasonable pumping depth.

\section{ACKNOWLEDGEMENTS}

This paper was supported by the Major National Science and Technology Project (Grant No.: 2016ZX05060) and the Key Science and Technology Project of the "Ten Dragons Program" of Sinopec (Grant No.: P18052).

\section{REFERENCES}

[1] Jennings, J.W. (1989). The Design of Sucker Rod Pump Systems. SPE Centennial Symposium at New Mexico Tech, Socorro, New Mexico. https://doi.org/10.2118/20152-MS

[2] Neely, A.B., Tolbert, H.O. (1988). Experience with pumpoff control in the Permian basin. Journal of Petroleum Technology, 40(5): 645-649. https://doi.org/10.2118/14345-PA

[3] Dunham, C.L. (1987). Supervisory control of beam pumping wells. SPE Production Operations Symposium, Oklahoma City, Oklahoma. https://doi.org/10.2118/16216-MS

[4] Hao, Z.X., Zhu, S.J., Pei, X.H., Huang, P., Tong, Z., Wang, B.Y., Li, D.Y. (2019). Submersible direct-drive progressing cavity pump rodless lifting technology. Petroleum Exploration and Development, 46(3): 621628. https://doi.org/10.1016/S1876-3804(19)60042-X

[5] Sultabayev, A. (2020, October). Advanced rod pump optimization approach-case study. SPE Annual Caspian Technical Conference, Virtual. https://doi.org/10.2118/202555-MS

[6] Tugan, M.F. (2020). Deliquification techniques for conventional and unconventional gas wells: Review, field cases and lessons learned for mitigation of liquid loading. Journal of Natural Gas Science and Engineering, 103568. https://doi.org/10.1016/j.jngse.2020.103568

[7] Liu, H., Meng, S., Su, J., Zhang, G., Chen, L. (2019). Reflections and suggestions on the development and engineering management of shale gas fracturing technology in China. Natural Gas Industry B, 6(6): 539545. https://doi.org/10.1016/j.ngib.2019.04.003

[8] Zhang, Z., Peng, S., Ghassemi, A., Ge, X. (2016). Simulation of complex hydraulic fracture generation in reservoir stimulation. Journal of Petroleum Science and
Engineering,

146 :

$272-285$

https://doi.org/10.1016/j.petrol.2016.04.037

[9] Orozco, D., Aguilera, R. (2017). A material-balance equation for stress-sensitive shale-gas-condensate reservoirs. SPE Reservoir Evaluation \& Engineering, 20(1): 197-214. https://doi.org/10.2118/177260-PA

[10] Liu, M., Tan, L., Xu, Y., Cao, S. (2020). Optimization design method of multi-stage multiphase pump based on Oseen vortex. Journal of Petroleum Science and Engineering, 184 : 106532. https://doi.org/10.1016/j.petrol.2019.106532

[11] You, X., Jia, C., Liu, J., Liao, X., Zheng, A., Li, J. (2019). A new production data analysis method of shale gas: based on flowing material balance theory and considering the complex flow mechanisms of multiple pressure systems. Energy Procedia, 158: 3626-3632. https://doi.org/10.1016/j.egypro.2019.01.900

[12] Turner, R.G., Hubbard, M.G., Dukler, A.E. (1969). Analysis and prediction of minimum flow rate for the continuous removal of liquids from gas wells. Journal of Petroleum Technology, 21(11): 1475-1482. https://doi.org/10.2118/2198-PA

[13] Coleman, S.B., Clay, H.B., McCurdy, D.G., Norris III, L.H. (1991). A new look at predicting gas-well load-up. Journal of Petroleum Technology, 43(3): 329-333. https://doi.org/10.2118/20280-PA

[14] Guo, B., Ghalambor, A., Xu, C. (2006). A systematic approach to predicting liquid loading in gas wells. SPE Production \& Operations, 21(1): 81-88. https://doi.org/10.2118/94081-PA

[15] Nosseir, M.A., Darwich, T.A., Sayyouh, M.H., El Sallaly, M. (2000). A new approach for accurate prediction of loading in gas wells under different flowing conditions. SPE Production \& Facilities, 15(4): 241-246. https://doi.org/10.2118/66540-PA

[16] Li, M., Li, S.L., Sun, L.T. (2002). New view on continuous-removal liquids from gas wells. SPE Production \& Facilities, 17(1): 42-46. https://doi.org/10.2118/75455-PA

[17] Wang, Y.Z., Liu, Q.W. (2007). A new method to calculate the minimum critical liquids carrying flow rate for gas wells. Petroleum Geology \& Oilfield Development in Daqing, 26(6): 82-85.

[18] Belfroid, S., Schiferli, W., Alberts, G., Veeken, C.A.M., Biezen, E. (2008). Prediction onset and dynamic behavior of liquid loading gas wells. SPE Annual Technical Conference and Exhibition, Denver, Colorado, USA. https://doi.org/10.2118/115567-MS

[19] Liu, S.Q., Wang, X.X., Li L., Feng, J.S., Liao, R.Q., Wang, X.W. (2018). Critical liquid-carrying model for horizontal gas well. International Journal of Heat and Technology, 36(4): https://doi.org/10.18280/ijht.360419

[20] Zhang, Z., Liao, R.Q., Fu, P., Su, Y.B., Luo, W., Zhang, D.X. (2018). Critical gas velocity prediction for vortex drainage gas wells. International Journal of Heat and Technology, 36(4): $1456-1462$. https://doi.org/10.18280/ijht.360439

[21] Shi, J., Sun, Z., Li, X. (2016). Analytical models for liquid loading in multifractured horizontal gas wells. SPE Journal, 21(2): 471-487. https://doi.org/10.2118/20141922861-PA 